\title{
Prevalence of Metabolic Syndrome (MetS) and Determinants Among Obese Teachers in Makassar, Indonesia
}

Nurzakiah Hasan, MKM ${ }^{a}$, Veni Hadju ${ }^{b}$, Nurhaedar Jafar ${ }^{b}$ \& Ridwan M. Thaha

${ }^{a}$ Health College Baramuli Pinrang, South Sulawesi, Indonesia

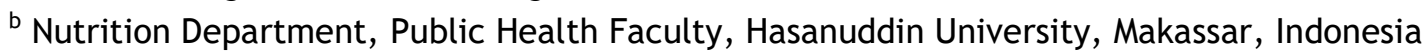

${ }^{c}$ Health Promotion Department, Public Health Faculty, Hasanuddin University, Makassar, Indonesia

\section{INTRODUCTION}

Metabolic Syndrome (MetS) is related to the increased risk of non-communicable diseases (NCDs). Teacher profession is an adult group with various risks of NCDs. This study aims to assess the determinants of the MetS in teachers with central obesity. Material and Methods: The study was conducted in Makassar, South Sulawesi, Indonesia with cross- sectional study design on 12 secondary schools. The number of samples in this study was 129 teachers. The prevalence of the MetS was determined using criteria from the Joint Interim Statement, while physical activity and sitting time were measured using the International Physical Activity Questionnaire (IPAQ). Results: Respondents in our study were mostly women $(\mathbf{7 8 . 3} \%$ ) with an average age of 49.8 years. The prevalence of the MetS in our study population was $39.5 \%$. The prevalence of the Mets was higher in Buginese ethnic $(70.6 \%)$, respondents with more income $(56.9 \%)$, bachelor degree $(80.4 \%)$, married $(98 \%)$, family history of diabetes mellitus, obesity, hypertension and heart diseases $(52.9 \%)$, and moderate physical activity (37.3\%). There was a significant relationship between sitting time ( $\geq 4$ hours; $p=0.004$ ), parameters of Mets $(p<0.001)$, LDL $(p=0.026)$, and LDL/HDL ratio $(p<0.001)$ with the Mets. Conclusions: The prevalence of the Mets is high among obese teachers in our study population. Sitting time was an important determinant for MetS among obese teachers.

KEYWORDS: Metabolic syndrome, determinants, sitting time INTRODUCTION

The prevalence of metabolic syndrome (MetS) ${ }^{1}$ continues to increase worldwide including Asia Pacific region. ${ }^{2}$ The increasing prevalence of MetS in China, Hong Kong, Taiwan, Japan, The Philippines, and Singapore is mainly due to increase in the central obesity. ${ }^{3}$ Research conducted in Indonesia shown that the prevalence of MetS was $28.4 \%$ in Jakarta ${ }^{4}$ and $18.2 \%$ in Bali ${ }^{5}$.

MetS is related to the increased risk of various non-communicable Diseases (NCDs) including cardiovascular disease and type 2 diabetes mellitus. ${ }^{6,7}$ Cardiovascular disease risk increases two

\section{Corresponding Author:}

Dr. Nurzakiah Hasan, Health College Baramuli Pinrang,

Pole Baramuli Street 91215 South Sulawesi, Indonesia.

Tel no: (0421) 924870/+6281342226001.

Email: nurzakiahksruh@gmail.com;

nurzakiah15p@student.unhas.ac.id times in a person who was diagnosed to have Met $S^{8}$ whereas type 2 diabetes mellitus risk increases five times in a person with MetS. ${ }^{6}$ A Meta-analysis performed in various studies of cancer, showing an increased risk of 1.1 to 1.6 times cancer in people who were already diagnosed with metabolic syndrome. ${ }^{9}$

The parameters used for diagnosis of the MetS are blood sugar, abdominal circumference, blood pressure, HDL cholesterol, and triglyceride levels. ${ }^{10}$ Having abnormal readings of three of these parameters indicates the risk of MetS. ${ }^{11}$

Teacher profession is an adult group with various risks $\mathrm{NCDs}^{12,13}$. A heavy workload ${ }^{14}$ has to be faced every day by these groups of people. High stress ${ }^{15,16}$ experienced by teachers increases the risk of NCDs. ${ }^{17}$ The risk increases with an increase of other determinants, such as family history of diseases such as diabetes mellitus, hypertension, and cardiovascular 
disease, age ${ }^{17}$ and lack of physical activity ${ }^{18}$. The working environment may also contribute to the risk of NCDs ${ }^{19}$.

South Sulawesi is the province with the highest stroke prevalence in Indonesia. ${ }^{20}$ The main risk factor for stroke is MetS. ${ }^{6}$ The study of the MetS and its parameters can have a positive implication in the treatment of the MetS at individual level ${ }^{21}$ and the prevention at population level. ${ }^{22} \mathrm{~A}$ meta-analysis shows that Indonesia still needs a lot of research related to social determinants as an effort to prevent NCDs. ${ }^{23}$ Central obesity is one risk factor that triggers various risks of NCDs. ${ }^{24},{ }^{25}$ This study aims to assess the prevalence determinants of the MetS in teachers who have central obesity.

\section{MATERIALS AND METHODS}

\section{Study Population}

This research was conducted in urban areas of Makassar City, South Sulawesi, Indonesia. It was a cross-sectional study among teachers in 12 secondary schools in Makassar City. The selection of schools was based on the largest number of teachers from all the selected three sub-districts, Biringkanayya, Tamalanrea and Manggala. Of the three sub-districts, two senior high schools and two junior high schools were chosen based on the highest number of teachers in each sub-district.

Sampling method was not random. Exclusion criteria for this study was pregnant women while inclusion criteria were civil servant teachers. A total of 386 teachers were interviewed and their anthropometries (body weight, height, and waist circumference) were measured for central obesity screening. Out of 386 teachers, a total of 229 teachers was noted to be obese (59.3\%), but only 151 teachers were willing to have the blood test. Samples who had been diagnosed with heart disease, diabetes mellitus, and cancer were excluded from the analysis ( $n=22$ people) as metabolic syndrome is a risk factor for these diseases. The total number of samples analysed was 129 teachers ( 28 men and 101 women).

\section{Anthropometric Measurement}

The anthropometric measurement was performed using calibrated tools. The weight was measured using an electronical medical scale (Camry), height was measured using microtoise, and the waist circumference was measured using measuring tape. Data on the characteristics of respondents (age, sex, ethnicity, marital status, education level, income level, family disease history) and anthropometric measurements were undertaken by trained personnel with an educational background of the nutrition department of public health faculty Hasanuddin University.

\section{Physical Activity}

Physical Activity and sitting time were measured with International Physical Activity Questionnaire (IPAQ) ${ }^{26}$ Physical activity is categorized as follows:

1. Low: if not moderate or vigorous

2. Moderate:

a. 3 or more days of vigorous-intensity activity of at least 20 minutes perday OR

b. 5 or more days of moderate-intensity activity and/or walking of at least 30 minutes per day OR

C. 5 or more days of any combination of walking, moderate-intensity or vigorous intensity activities achieving a minimum.

3. High:

a. Vigorous intensity on at least 3 days $(20$ minimum), achieving a minimum total physical activity at least 1,500 MET-minutes/ week

OR

b. 7 or more days of any combination of walking, moderate-intensity or vigorous intensity activities were achieving a minimum Total physical activity of at least 3,000 METminutes/week.

\section{Laboratory Measurement}

Blood collection was done by trained personnel from Prodia Laboratory. All participants were required to not to take orally (except for plain water) for at least 12-14 hours prior to blood sampling. HDL and LDL cholesterol was analysed using homogeneous enzymatic colorimetric assay method; triglyceride by the enzymatic colorimetric method; cholesterol by cholesterol oxidase method and fasting glucose by the hexokinase method. 


\section{Code of Ethics}

This study is a preliminary study for a cohort study on the preparation of balanced nutrition modules in teachers as an effort to prevent MetS. All participants have filled up the informed consent form to take part in this study. This research has obtained code of ethics from the Medical Research Ethics Commission of the Faculty of Medicine RSPTN Hasanuddin University with protocol number UH17080549.

\section{Metabolic Syndrome Definition}

MetS is defined using criteria from the Intemational Diabetes Federation (IDF) ${ }^{10}$. Respondents are at risk of MetS if their triglyceride levels $\geq 150 \mathrm{mg} / \mathrm{dl}, \mathrm{HDL}$ ( $<40 \mathrm{mg} / \mathrm{dl}$ for men and $<50 \mathrm{mg} / \mathrm{dl}$ for women), fasting blood glucose $\geq 100 \mathrm{mg} / \mathrm{dl}$, or blood pressure $\geq 130 / 85 \mathrm{mmHg}$. Central obesity is determined by Asian, ethnic, risk if ( $\geq 90 \mathrm{~cm}$ in men and $\geq 80 \mathrm{~cm}$ in women). Respondents were diagnosed with MetS if they have $\geq 3$ parameters ${ }^{27}$.

\section{Statistical analysis}

The data were described by mean and standard deviation values. For categorical variables Chi-square analysis was used, whereas t-test (normal distributed data) was used for data ratio. Binary logistic regression was performed to assess the association between sitting time, HDL, FBG, TG, SBP and MetS. Statistical analysis was performed using SPSS version 17.

\section{RESULTS}

\section{Social Characteristics of Respondents}

General characteristics of respondents stratified by sex are presented in Table I. Respondents were mostly women $(78.3 \%)$ with an average age of 49.8 years. The majority of the respondents were Buginese (65.9\%), Moslem (92.2\%), married (96.1\%), and have bachelor degree education (81.4\%). Respondents are mainly from moderate income (> $4,300.000)$ group $(58.1 \%)$ (Table I).

\section{Prevalence of Mets Determinant}

The prevalence of the MetS in the study population was $39.5 \%$ and the number of prevalence is higher in women $(68.6 \%$ vs. $31.4 \%)$ (Table II). The most significant parameters in men

Table I. Sosial characteristic respondents between sex

\begin{tabular}{|c|c|c|c|c|}
\hline \multirow{2}{*}{$\begin{array}{l}\text { Social Characteristic } \\
\text { Respondents }\end{array}$} & $\begin{array}{c}\text { Men } \\
(n=28)\end{array}$ & $\begin{array}{l}\text { Women } \\
(\mathrm{n}=101)\end{array}$ & $\begin{array}{c}\text { Total } \\
(\mathrm{n}=129)\end{array}$ & $p$ value \\
\hline & $\%$ & $\%$ & $\%$ & \\
\hline Age, year, mean (SD) & $\begin{array}{l}47.9 \\
(8.4)\end{array}$ & $\begin{array}{l}49.8 \\
(7.4)\end{array}$ & $\begin{array}{l}49.8 \\
(7.4)\end{array}$ & 0.249 \\
\hline \multicolumn{5}{|l|}{ Ethnic } \\
\hline Buginese & 71.4 & 64.4 & 65.9 & 0.478 \\
\hline Makassarese & 17.9 & 12.9 & 14 & \\
\hline Mandarese & 3.6 & 12.9 & 10.9 & \\
\hline Others & 7.1 & 9.9 & 9.2 & \\
\hline \multicolumn{5}{|l|}{ Agama } \\
\hline Moslem & 96.4 & 91.1 & 92.2 & 0.316 \\
\hline Kristen & 3.6 & 8.9 & 7.8 & \\
\hline \multicolumn{5}{|l|}{ Marital Status } \\
\hline Unmarried/Divorce & 3.6 & 4 & 3.9 & 0.703 \\
\hline Married & 96.4 & 96 & 96.1 & \\
\hline \multicolumn{5}{|l|}{ Level of Education } \\
\hline High School/College & 3.6 & 3 & 3.1 & 0.281 \\
\hline \multicolumn{5}{|l|}{ Degree } \\
\hline Bachelor Degree & 71.4 & 84.2 & 81.4 & \\
\hline Master/Doctoral Degree & 25 & 12.9 & 15.5 & \\
\hline \multicolumn{5}{|l|}{ Income (mean) } \\
\hline$\leq 4.300 .000$ & 57.1 & 37.6 & 41.9 & 0.102 \\
\hline$>4.300 .000$ & 42.9 & 62.4 & 58.1 & \\
\hline
\end{tabular}


were low HDL and high Triglyceride levels (57.1\%, $57.1 \%)$, whereas in women was high HDL only (53.5\%) (Figure 1). The prevalence of MetS did not show any significant association with age group $(p>0.05)$ but was noted that increasing age increased the MetS

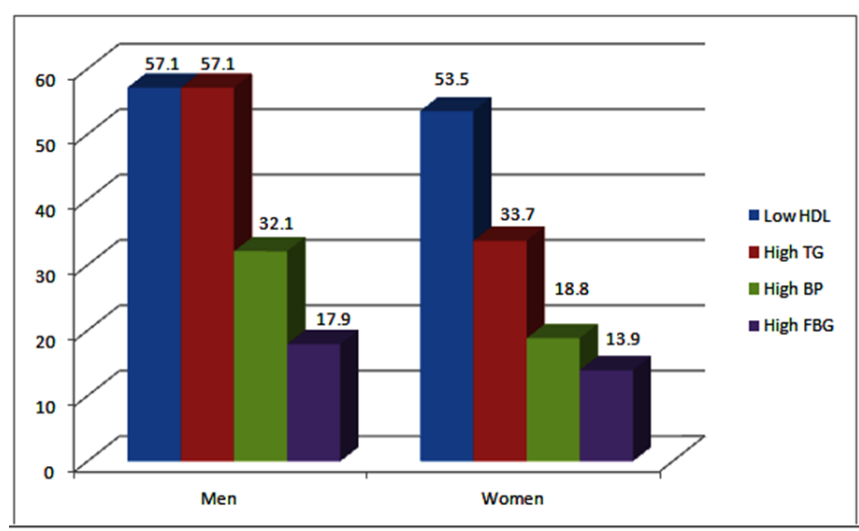

Figure 1: The proportion of MetS components between sex.

There was no association between prevalence of the MetS with an ethnic group, income level, education level, marital status and family history of diseases (diabetes mellitus, hypertension, heart disease, and obesity) ( $>0.05)$. However, the prevalence of the MetS was higher in Buginese $(70,6 \%)$, higher income $(56,9 \%)$, bachelor degree $(80,4 \%)$, married $(98 \%)$ and have a family history of diseases $(52,9 \%)$. Prevalence of the MetS was higher in respondent with moderate physical activity (37.3\%). The sitting time of the respondents showed a significant association with the MetS ( $p=0.004)$, in which the respondents who sat more than 4 hours a day have a higher risk of having MetS than those sitting $<4$ hours $(51.0 \%, 49 \%)$ (Table II).

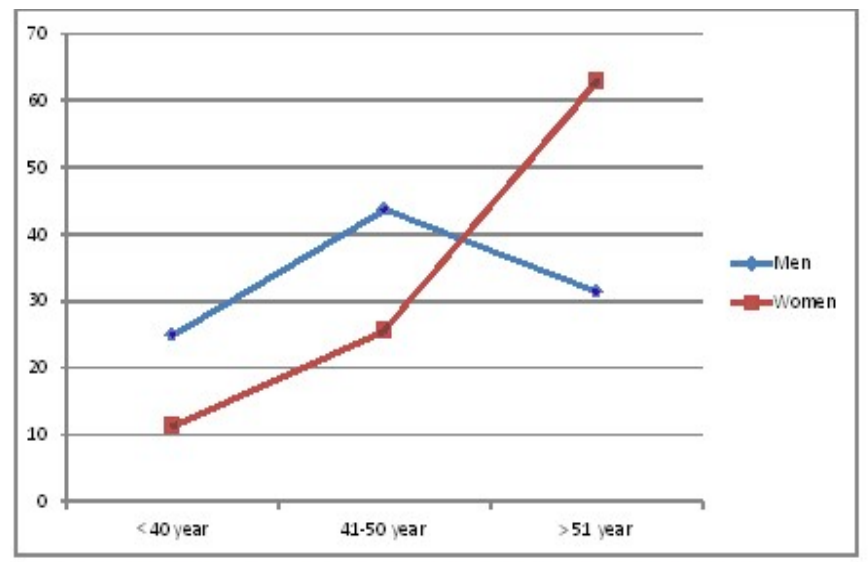

Figure 2. Prevalence a metabolic syndrome by age group after stratification by sex

The mean of BMI in the respondents who had MetS was higher than those at risk $(p=0.041)$. All MetS parameters showed a significant association with the MetS $(p<0.05)$.
Table II. Prevalence of Metabolic syndrome based on the social characteristic of respondents

\begin{tabular}{|c|c|c|c|}
\hline & $\begin{array}{c}\begin{array}{c}\text { Metabolic } \\
\text { Syndrome } \\
(n=51) \\
\%\end{array} \\
\end{array}$ & $\begin{array}{c}\text { Risk of } \\
\text { Metabolic } \\
\text { Syndrome } \\
(\mathrm{n}=78) \\
\%\end{array}$ & P value \\
\hline \multicolumn{4}{|l|}{ Sex } \\
\hline Male & 31.4 & 15.4 & 0.053 \\
\hline Age ${ }^{\text {Female }}$ & 68.6 & 84.6 & \\
\hline$<40$ Years & 15.7 & 14.1 & 0.925 \\
\hline 40 - 50 Years & 31.4 & 29.5 & \\
\hline$>51$ Years & 52.9 & 56.4 & \\
\hline \multicolumn{4}{|l|}{ Ethnic } \\
\hline Buginese & 70.6 & 62.8 & 0.757 \\
\hline Makassarese & 13.7 & 14.1 & \\
\hline Mandarese & 7.8 & 12.8 & \\
\hline $\begin{array}{c}\text { Others } \\
\text { Income (mean) }\end{array}$ & 7.8 & 10.3 & \\
\hline$\leq 4.300 .000$ & 43.1 & 41.0 & 0.956 \\
\hline$>4.300 .000$ & 56.9 & 59.0 & \\
\hline \multicolumn{4}{|l|}{$\begin{array}{l}\text { Level of } \\
\text { education }\end{array}$} \\
\hline $\begin{array}{l}\text { High } \\
\text { school/ } \\
\text { College } \\
\text { Degree }\end{array}$ & 2.0 & 3.8 & 0.736 \\
\hline $\begin{array}{l}\text { Bachelor } \\
\text { Degree }\end{array}$ & 80.4 & 82.1 & \\
\hline $\begin{array}{l}\text { Master/ } \\
\text { Doctoral } \\
\text { Degree }\end{array}$ & 17.6 & 14.1 & \\
\hline \multicolumn{4}{|l|}{ Marital Status } \\
\hline $\begin{array}{l}\text { Unmarried/ } \\
\text { divorce }\end{array}$ & 2.0 & 5.1 & 0.656 \\
\hline Married & 98.0 & 94.9 & \\
\hline \multicolumn{4}{|l|}{ Family history } \\
\hline $\begin{array}{l}\text { DM/ obese/ } \\
\text { HT/Heart } \\
\text { disease } \\
\text { No }\end{array}$ & 52.9 & 61.5 & 0.15 \\
\hline \multicolumn{4}{|l|}{ Physical Activity } \\
\hline $\begin{array}{l}\text { Low } \\
\text { Moderate }\end{array}$ & $\begin{array}{l}33.9 \\
37.3\end{array}$ & $\begin{array}{l}33.3 \\
44.9\end{array}$ & 0.563 \\
\hline High & 29.4 & 21.8 & \\
\hline \multicolumn{4}{|l|}{ Sitting Time } \\
\hline $\begin{array}{l}\geq 4 \text { hours } \\
<4 \text { hours }\end{array}$ & $\begin{array}{l}51 \\
49\end{array}$ & $\begin{array}{l}24.4 \\
75.6\end{array}$ & $0.004^{*}$ \\
\hline
\end{tabular}

The total cholesterol mean is higher in those with the MetS than at risk, but did not show a significant association ( $p=0.066)$. High LDL levels, as well as LDL/ $\mathrm{HDL}$ ratios also showed significant differences between those with the MetS and at risk (Table III).

Table IV shows the multivariate analysis of variables associated with the MetS. Five variables were sitting time, HDL, FBG, TG and SBP. It was shown that sitting time was the important determinant in this study $(\mathrm{OR}=5.391, \mathrm{Cl}=1.071-27.175)$. 
Table III. Association between clinical parameters and Metabolic Syndrome

\begin{tabular}{llll}
\hline & $\begin{array}{l}\text { Metabolic } \\
\text { Syndrome } \\
(\mathbf{n}=51)\end{array}$ & $\begin{array}{l}\text { Risk of } \\
\text { Metabolic } \\
\text { syndrome } \\
(\mathbf{n}=78)\end{array}$ & P value \\
\cline { 2 - 4 } & Mean \pm SD & Mean \pm SD & \\
\hline BMI & $28.8 \pm 3.2$ & $27.5 \pm 3.63$ & $0.041^{*}$ \\
HDL & $38.4 \pm 8.4$ & $52.9 \pm 11.7$ & $<0.001^{* *}$ \\
FBG & $96.2 \pm 27.0$ & $84.7 \pm 19.8$ & $0.011^{*}$ \\
TG & $231.2 \pm 121.3$ & $107.4 \pm 33.8$ & $<0.001^{* *}$ \\
SBP & $127.4 \pm 15.6$ & $117.5 \pm 13.2$ & $<0.001^{* *}$ \\
DBP & $84.1 \pm 9.6$ & $78.3 \pm 9.7$ & $0.001^{* *}$ \\
Total & $244.8 \pm 41.3$ & $229.0 \pm 50.8$ & 0.066 \\
Cholesterol & $172.9 \pm 36.2$ & $155.7 \pm 45.9$ & $0.026^{*}$ \\
LDL & $4.6 \pm 1.1$ & $3.3 \pm 2.2$ & $<0.001^{* *}$ \\
LDL/HDL & & & \\
Ratio & & & \\
\hline${ }^{*}$ p $<0.05$ & & & \\
\hline$* 0.01$ & & & \\
\hline BML $:$ Body Mass & & & \\
\hline
\end{tabular}

BMI : Body Mass Index; HDL: High Density Lipoprotein; FBG : Fasting Blood Glucose

TG : Triglycerides ; SBP : Systolic Blood Pressure; DBP: Diastolic Blood Pressure

LDL : Low Density lipoprotein; LDL/HDL ratio : Low density lipoprotein/High Density lipoprotein ratio

\section{DISCUSSION}

The prevalence of MetS in this study was $39.5 \%$, higher than the prevalence in Middle East countries ${ }^{28}$ or Asian countries. ${ }^{3,29,30}$ The high prevalence of the MetS was noted in our study as the samples has been identified by having central obesity, making them having one pre-existing risk parameter. The study was conducted on a group of teachers with a low level of physical activity due to their working environment ${ }^{19}$. A low level of physical activity is known to be associated with an increased risk of metabolic syndrome ${ }^{31}$.

Prevalence in women is higher than in men $(68.6 \%$; $31.4 \%)$. The result was similar with some previous studies $^{32-34}$ except for those conducted in Malaysia ${ }^{35}$.
Women are at greater risk of various NCDs than men as some risk factors are specific to women such as pregnancy factors (high blood pressure due to pregnancy, gestational diabetes, placental disorder, and fetal growth), and menopause. ${ }^{36}$ Nevertheless, differences in the prevalence of MetS in both women and men showed a borderline relationship $(p=0.053)$. The findings otherwise showed $a$ relationship between gender and MetS ${ }^{37}$. This can be explained by differences of fat distribution in men and women; and the hormonal regulatory differences. $^{38}$

$\mathrm{HDL}$ and triglyceride levels are the most significant parameters in men while in women is HDL levels. Our results are similar with studies conducted in the Philippines, which shown the prevalence of MetS in men is associated with elevated triglyceride levels, blood pressure and fasting blood glucose, while the prevalence in women is associated with the lower levels of HDL and increase of abdominal circumference. ${ }^{29}$ Low HDL levels are the most risky parameter in some countries in Asia Pacific. ${ }^{29,39}$

Our study results show the increase of age will also increase the prevalence of the MetS in women, whereas in men it increases in the age group 40-50 years but declines after the age of 51 years. Increased life also increases the risk of various NCDs including MetS $^{33}$. In the EpiHealth cohort study conducted in Sweden, it was found out that weight gain change was a major factor for the increased prevalence of MetS with age ${ }^{40}$.

In our study, the prevalence of the MetS was are higher among those who have a family history of diabetes mellitus or obesity or hypertension or heart disease than those without a history of the diseases (52.9\%; 47.1\%). A national study in Sri Lanka showed that respondents who have a family history of

Table IV. Multivariate Analysis of Sitting Time and Clinical Parameters in relation to Metabolic Syndrome

\begin{tabular}{llllllll}
\hline Variables & B & S.E & Wald & df & Sig. & $\begin{array}{l}\text { Odds } \\
\text { Ratio }\end{array}$ & $95 \% \mathrm{Cl}$ \\
\hline Sitting Time & 1,685 & 0.825 & 4,168 & 1 & 0.041 & 5,391 & $1.070-27.175$ \\
HDL & 0.159 & 0.049 & 10,364 & 1 & 0.001 & 1,172 & $1.064-1.291$ \\
FBG & -0.060 & 0.021 & 8,465 & 1 & 0.004 & 0.942 & $0.904-0.981$ \\
TG & -0.053 & 0.013 & 16,118 & 1 & 0.000 & 0.948 & $0.924-0.973$ \\
SBP & -0.094 & 0.038 & 6,250 & 1 & 0.012 & 0.910 & $0.845-0.980$
\end{tabular}


hypertension have a greater risk of having MetS (OR: 1,19; $95 \% \mathrm{Cl}: 1,08-1,30) .{ }^{41}$ Screening family history is a practical approach to prevention of NCDs. ${ }^{42}$

From our study, there was no relationship between the physical activity with the MetS $(p>0.05)$. The result was similar with some previous. ${ }^{43,44}$ Our study shows the prevalence of the metabolic syndrome was highest in respondents who did a moderate activity (37.3\%) but low in respondents who did a vigorous physical activity (29.4\%). A previous study by Janssen et al., showed that vigorous physical activity can reduce risk of MetS by $37.1 \%$ compared to moderate physical activity (15.5\%). ${ }^{45} \mathrm{~A}$ regular physical activity is closely related to MetS parameters (waist circumference, HDL levels, and blood pressure). ${ }^{46}$

The sitting time showed a significant association with the MetS\{Gómez-Cabello, $2012 \# 1124\}$. This is similarly same with studies conducted in Spain in which respondents who sat more than 4 hours are more at risk of central obesity than those sitting less than 4 hours $(p<0.001) .{ }^{47}$ An intervention study in Australia showed the positive health benefits after reducing sitting time on their respondents ${ }^{48}$ by decreases LPL enzyme activity (lipoprotein lipase) which is the main enzyme to regulate fat metabolism (triglyceride). ${ }^{49}$

In our study, the mean BMI in the respondents who had metabolic syndrome were higher than those at risk $(p=0.041)$. The study of non-obese teachers in Malaysia showed an increase in MetS as BMI increased. ${ }^{29}$ All MetS parameters showed a significant association with the MetS $(p<0.05)$. This result is similar to previous research in several countries in Asia Pacific. ${ }^{29,39}$

In this study, high LDL and LDL/HDL ratios, were noted to be higher in respondents with the MetS than at risk and show a significant association with the MetS. Several previous studies have shown LDL and LDL/HDL ratio with MetS. ${ }^{50}$ The LDL/HDL ratio is a better marker to account for cardiovascular risk. ${ }^{51}$ Regular lipid profile examination in certain age groups is important to detect the risk of developing MetS. ${ }^{52}$

From our study, the sitting time was shown to be an important determinant as our study sample were teachers with moderate activity. A high sitting time in teachers contributes to lower perceived mental and physical health. ${ }^{53} \mathrm{~A}$ high sitting time increases the risk of obesity ${ }^{47}$ that is one of the MetS parameters. ${ }^{7}$ There were two limitations of this study. Firstly, it is a cross-sectional study, therefore a causal relationship cannot be inferred from this study. Secondly, it was conducted on a group of teachers dominated by female $(78.29 \%)$, as well as other research in some other countries. ${ }^{53}$

This study concludes that the prevalence of the MetS is high in the group of teachers who have central obesity. The most significant parameters in men were the HDL and triglyceride levels while in women was the HDL levels. There was an increased risk of Mets as the women's age but not in men. The prevalence of the MetS is higher in respondents who have a family history of DM, HT, obesity and heart disease. There was a significant association between sitting time, LDL, and LDL ratio with the MetS. An Intervention study related sitting time to a group of teachers is needed to reduce the risk of the MetS.

\section{CONFLICT OF INTEREST}

The authors declare no conflict of interest

\section{REFERENCES}

1. O'Neill S, O'Driscoll L. Metabolic syndrome: a closer look at the growing epidemic and its associated pathologies. obesity reviews. 2015;16 (1):1-12.

2. Ranasinghe $P$, Mathangasinghe $Y$, Jayawardena $R$, Hills A, Misra A. Prevalence and trends of metabolic syndrome among adults in the asiapacific region: a systematic review. BMC public health. 2017;17(1):101.

3. Nestel P, Lyu R, Low LP, et al. Metabolic syndrome: recent prevalence in East and Southeast Asian populations. Asia Pacific journal of clinical nutrition. 2007;16(2):362.

4. Soewondo P, Purnamasari D, Oemardi $M$, Waspadji S, Soegondo S. Prevalence of metabolic syndrome using NCEP/ATP III criteria in Jakarta, Indonesia: the Jakarta primary noncommunicable disease risk factors surveillance 2006. Acta Med Indones. 2010;42(4):199-203.

5. Suastika K, Dwipayana P, Saraswati IMR, et al. Prevalence of obesity, metabolic syndrome, impaired fasting glycemia, and diabetes in selected villages of Bali, Indonesia. Journal of the 
ASEAN Federation of Endocrine Societies.

2014;26(2):159.

6. Grundy SM. Metabolic syndrome update. Trends in Cardiovascular Medicine. 2016/05/01/ 2016;26(4):364-373.

7. Kaur J. A comprehensive review on metabolic syndrome. Cardiology research and practice. 2014;2014.

8. Han TS, Lean ME. A clinical perspective of obesity, metabolic syndrome and cardiovascular disease. JRSM cardiovascular disease. 2016;5:2048004016633371.

9. Esposito K, Chiodini P, Colao A, Lenzi A, Giugliano D. Metabolic Syndrome and Risk of Cancer A systematic review and meta-analysis. Diabetes Care. 2012;35(11):2402-2411.

10. Alberti K, Eckel RH, Grundy SM, et al. Harmonizing the metabolic syndrome a joint interim statement of the international diabetes federation task force on epidemiology and prevention; national heart, lung, and blood institute; American heart association; world heart federation; international atherosclerosis society; and international association for the study of obesity. Circulation. 2009;120(16):1640-1645.

11. Grundy SM. Pre-diabetes, metabolic syndrome, and cardiovascular risk. Journal of the American College of Cardiology. 2012;59 (7):635-643.

12. Adeniyi, Aderemi B, Laurence, et al. Prevalence of chronic kidney disease and association with cardiovascular risk factors among teachers in Cape Town, South Africa. Clinical Kidney Journal. 2017:138.

13. Domingo, Abdul Kader Asmal, Laila Seedat, et al. Investigating the association between diabetes mellitus, depression and psychological distress in a cohort of South African teachers. SAMJ: South African Medical Journal. 2015;105 (12):1057-1060.

14. Bauer, Joachim, Unterbrink, et al. Working conditions, adverse events and mental health problems in a sample of 949 German teachers. International archives of occupational and environmental health. 2007;80(5):442-449.

15. Samad NIA, Hashim Z, Moin S, Abdullah H. Assessment of stress and its risk factors among primary school teachers in the Klang Valley, Malaysia. Global Journal of Health Science. 2010;2(2):163.
16. Bergmann., Natasha C, Gyntelberg., Finn F, Jens. Chronic stress and the development of the metabolic syndrome: a systematic review of prospective cohort studies. Endocrine connections. 2014:EC-14-0031.

17. Belfki $\mathrm{H}, \mathrm{Ali} \mathrm{SB}$, Aounallah-Skhiri $\mathrm{H}$, et al. Prevalence and determinants of the metabolic syndrome among Tunisian adults: results of the Transition and Health Impact in North Africa (TAHINA) project. Public Health Nutrition. 2013;16(04):582-590.

18. Edwardson, Charlotte L Gorely, Trish Davies, et al. Association of sedentary behaviour with metabolic syndrome: a meta-analysis. PloS one. 2012;7(4):e34916.

19. Diasl, Douglas Fernando Lochll MRG, Alberto Durán de AndradellI, Selma Maffei MesasIII, , Eumann A. Insufficient free-time physical activity and occupational factors in Brazilian public school teachers. Rev Saude Publica. 2017;51:68.

20. Ministry oH. Basic Health Research Report of Indonesia. Jakarta: Ministry of Health Republic Indonesia;2013.

21. MCCracken E, Monaghan M, Sreenivasan S. Pathophysiology of the metabolic syndrome. Clinics in Dermatology. 2018/01/01/ 2018;36 (1):14-20.

22. Blackford, Krysten Jancey, Jonine Lee, et al. Home-based lifestyle intervention for rural adults improves metabolic syndrome parameters and cardiovascular risk factors: A randomised controlled trial. Preventive Medicine. 2016/08/01/ 2016;89(Supplement C):15-22.

23. Schröders J, Wall S, Hakimi M, et al. How is Indonesia coping with its epidemic of chronic noncommunicable diseases? A systematic review with meta-analysis. PLOS ONE. 2017;12

(6):e0179186.

24. Papaetis GS, Papakyriakou P, Panagiotou TN. Central obesity, type 2 diabetes and insulin: exploring a pathway full of thorns. Archives of medical science: AMS. 2015;11(3):463.

25. Goh LG, Dhaliwal SS, Welborn TA, Lee AH, Della PR. Anthropometric measurements of general and central obesity and the prediction of cardiovascular disease risk in women: a crosssectional study. BMJ open. 2014;4(2):e004138.

26. Craig $\mathrm{CL}$, Marshall $\mathrm{AL}$, Sjorstrom $\mathrm{M}$, et al. International physical activity questionnaire: 12 -country reliability and validity. Medicine and 
science in sports and exercise. 2003;35

(8):1381-1395.

27. Kassi E, Pervanidou P, Kaltsas G, Chrousos G. Metabolic syndrome: definitions and controversies. BMC medicine. 2011;9(1):48.

28. Ansarimoghaddam., Alireza., Adineh., et al. Prevalence of metabolic syndrome in MiddleEast countries: Meta-analysis of crosssectional studies. Diabetes \& Metabolic Syndrome: Clinical Research \& Reviews. 2017.

29. G. Sy R, Jasper B. Llanes E, Ferdinand M. Reganit $\mathrm{P}$, et al. Socio-demographic factors and the prevalence of metabolic syndrome among Filipinos from the LIFECARE cohort. Journal of atherosclerosis and thrombosis. 2014;21(Supplement1):S9-S17.

30. Lee SC, Hairi NN, Moy FM. Metabolic syndrome among non-obese adults in the teaching profession in Melaka, Malaysia. Journal of Epidemiology. 2017/03/01/2017;27(3):130134.

31. Li J, Siegrist J. Physical activity and risk of cardiovascular disease-a meta-analysis of prospective cohort studies. International journal of environmental research and public health. 2012;9(2):391-407.

32. Mabry R, Reeves M, Eakin E, Owen N. Gender differences in prevalence of the metabolic syndrome in Gulf Cooperation Council Countries: a systematic review. Diabetic Medicine. 2010;27(5):593-597.

33. Raposo L, Severo M, Barros H, Santos AC. The prevalence of the metabolic syndrome in Portugal: the PORMETS study. BMC public health. 2017;17(1):555.

34. Zhao Y, Yan H, Yang R, Li Q, Dang S, Wang Y. Prevalence and Determinants of Metabolic Syndrome among Adults in a Rural Area of Northwest China. PLoS ONE. 2014;9 (3):e91578.

35. Phing $\mathrm{CH}$, Saad HA, Yusof BNM, Taib MNM. Determinants of Metabolic Syndrome among Malaysian Government Employees. International Medical Journal Malaysia. 2018;17(1).

36. Appelman $\mathrm{Y}$, van Rijn BB, Monique E, Boersma $E$, Peters SA. Sex differences in cardiovascular risk factors and disease prevention.

Atherosclerosis. 2015;241(1):211-218.

37. Allal-Elasmi M, Taieb SH, Hsairi M, et al. The metabolic syndrome: prevalence, main characteristics and association with socio- economic status in adults living in Great Tunis. Diabetes \& metabolism. 2010;36(3):204-208.

38. Pradhan AD. Sex differences in the metabolic syndrome: implications for cardiovascular health in women. Clinical chemistry. 2014;60 (1):44-52.

39. Prasad D, Kabir Z, Dash A, Das B. Prevalence and risk factors for metabolic syndrome in Asian Indians: A community study from urban Eastern India. Journal of cardiovascular disease research. 2012;3(3):204-211.

40. Lind L, Elmståhl S, Ärnlöv J. Change in Body Weight from Age 20 Years is a Powerful Determinant of the Metabolic Syndrome. Metabolic syndrome and related disorders. 2017;15(3):112-117.

41. Ranasinghe, Priyanga, Cooray, et al. The influence of family history of hypertension on disease prevalence and associated metabolic risk factors among Sri Lankan adults. BMC Public Health. 2015;15(1):576.

42. Khanna N, Sharma R, Sidhu R. A study of the basic and derived anthropometric indices among the healthy adults (20-30 years of age) of amritsar city (punjab) having family history of hypertension. Int J Biol Med Res. 2011;2 (3):743-746.

43. Fadzlina A, Harun F, Nurul Haniza $M$, et al. Metabolic syndrome among 13 year old adolescents: prevalence and risk factors. BMC Public Health. November 24 2014;14(3):S7.

44. Fam B, Amouzegar A, Arzhan S, et al. Association between Physical Activity and Metabolic Risk Factors in Adolescents: Tehran Lipid and Glucose Study. International journal of preventive medicine. 2013;4(9):1011-1017.

45. Janssen I, Ross R. Vigorous intensity physical activity is related to the metabolic syndrome independent of the physical activity dose. International journal of epidemiology. 2012;41 (4):1132-1140.

46. Pattyn N, Cornelissen VA, Eshghi SRT, Vanhees $\mathrm{L}$. The effect of exercise on the cardiovascular risk factors constituting the metabolic syndrome. Sports medicine. 2013;43(2):121133.

47. Gómez-Cabello A, Pedrero-Chamizo R, Olivares $\mathrm{PR}$, et al. Sitting time increases the overweight and obesity risk independently of walking time in elderly people from Spain. Maturitas. 2012;73(4):337-343. 
48. Healy GN, Eakin EG, LaMontagne AD, et al. Reducing sitting time in office workers: shortterm efficacy of a multicomponent intervention. Preventive medicine. 2013;57 (1):43-48.

49. Zderic TW, Hamilton MT. Physical inactivity amplifies the sensitivity of skeletal muscle to the lipid-induced downregulation of lipoprotein lipase activity. Journal of Applied Physiology. 2006;100(1):249-257.

50. Gasevic D, Frohlich J, Mancini GBJ, Lear SA. Clinical usefulness of lipid ratios to identify men and women with metabolic syndrome: a cross-sectional study. Lipids in Health and Disease. 2014/10/10 2014;13(1):159.

51. Millán J, Pintó X, Muñoz A, et al. Lipoprotein ratios: physiological significance and clinical usefulness in cardiovascular prevention. Vascular health and risk management. 2009;5:757.

52. Kamso $\mathrm{S}$. Body mass index, total cholesterol, and ratio total to HDL cholesterol were determinants of metabolic syndrome in the Indonesian elderly. Medical Journal of Indonesia. 2007;16(3):195.

53. Bogaert, Inge De Martelaer, Kristine Deforche, Benedicte Clarys, Peter Zinzen, Evert. Associations between different types of physical activity and teachers' perceived mental, physical, and work-related health. BMC public health. 2014;14(1):1. 
